\title{
Histological Alterations Induced by Atorvastatin Therapeutic Doses in some Organs of Male Albino Rats
}

\author{
Twana Ahmed Mustafa $^{1 *}$, Hamza Osman Abdulah ${ }^{2}$ \\ ${ }^{1}$ Department of Med. Lab Technique, Erbil Polytechnic University, Health Technical College, Erbil, Iraqi Kurdistan, ${ }^{2}$ Department of \\ Histopathology, Shar Hospital, Sulaimania, Iraqi Kurdistan
}

\section{*Corresponding author: Twana Ahmed Mustafa, Department of Med. Lab Technique, Erbil Polytechnic University, Health Technical College, Erbil, Iraqi \\ Kurdistan. \\ E-mail: dr.twana@epu. edu.iq}

Received: 14 August 2018

Accepted: 01 March 2019

Published: 10 April 2019

\section{DOI}

10.25156/ptj.v9n1y2019.

pp13-16

\section{A B S T R A C T}

Vascular disease and heart attacks are a common phenomenon in the modern world, where lipid accumulates inside blood vessels and causes plug, eventually heart stroke and death. Utilize lipidlowering drugs are the most effective factors to prevent heart disease. Atorvastatin is the most important drugs that used in this field. The aim of this study was to investigate the adverse effects of atorvastatin $(20 \mathrm{mg} / \mathrm{kg} / \mathrm{b} . \mathrm{wt} / \mathrm{day})$ on some organs of albino. 12 adult male albino rats weighing $200 \pm 20 \mathrm{~g}$ were used and divided into two groups: First group served as control group, was given $0.72 \mathrm{ml}$ distilled water/rat. The second group was subjected to treatments with atorvastatin in a dose of $20 \mathrm{mg} / \mathrm{kg} / \mathrm{b} . \mathrm{wt} /$ day as a single daily dose $(0.72 \mathrm{ml}$ contained $1.44 \mathrm{mg}$ of atorvastatin) orally by gastric tube for 4 weeks. Histological alterations were examined, and the results of atorvastatintreated groups showed changes in the kidney sections, which include focal tubular edema and glomerular atrophy, also liver sections revealed foci of lymphocyte accumulation, cytoplasmic vacuolization, as well as sections of the testes showed degenerative changes in the seminiferous tubules. According to this study, we can conclude that atorvastatin-induced various deleterious changes in the histological structure of the testes, kidneys and cause mild liver alteration of adult male albino rat.

Keywords: Atorvastatin; Kidney; Liver; Rats; Testis

\section{INTRODUCTION}

Within the past 20 years, any textbook of cardiovascular medicine published the role of dyslipidemia in the development of both atherosclerosis and acute arterial thrombosis. Elevated total serum cholesterol, elevated low-density lipoprotein cholesterol (LDL-C), and decreased high-density lipoprotein cholesterol (HDL-C) are all well-established risk factors for coronary heart disease (Wierzbicki et al., 1999). Dyslipidemia is recognized as a prominent risk factor for cardiovascular disease (Miller, 2009).

Dyslipidemias include hypercholesterolemia and low levels of HDL and cholesterol. Hypercholesterolemia is a major cause of atherosclerosis and atherosclerosisinduced conditions such as coronary heart disease, ischemic cerebrovascular disease, and peripheral vascular disease. Recognition that dyslipidemia is a risk factor has led to the development of the drugs that modify cholesterol levels (Brunton et al., 2011).

Hypocholesterolemic drugs, such as statin and fibrate, are widely prescribed medications effective to reduce blood lipids level. Statins potently inhibit the 3-hydroxymethylglutaryl-coenzyme A reductase, the rate-limiting enzyme for the synthesis of mevalonate and, therefore, cholesterol (Goldstein and Brown, 1999).

Statins are currently the first-line pharmacologic therapy for hypercholesterolemia (Mostafa et al., 2015). Atorvastatin in dosage of $10-80 \mathrm{mg} /$ day reduces the levels of total cholesterol, LDL-C, triglyceride, and very LDL-C and increases HDL-C in patients with a wide variety of dyslipidemias (Mostafa et al., 2015).

The most serious adverse effect of statins is muscle injury. There are many reports on muscle and renal toxicity after taking statins in patients who have received these drugs. Iron released from the damaged muscle tissue contributes to renal toxicity as a source of iron. As an oxidant, iron causing damage to membrane oxidative of various cells including renal tubes (Vanholder et al., 2000; Bosch et al., 2009). Furthermore, a dose-dependent increase of liver enzymes can be noted with statins use (Pasternak et al., 2002). In animals, statins intake reduces sperm parameters. It increased the production of reactive oxygen species (Pal et al., 2015). 


\section{MATERIALS AND METHODS}

\section{Drugs}

Atorvastatin (Lipitor $20 \mathrm{mg}$ ) tablets were purchased from Pfizer Company for pharmaceutical and chemical industries. The drug was dissolved in $10 \mathrm{ml}$ distilled water and given orally by a gastric tube (Schmechel et al., 2009). The daily single oral dose was $20 \mathrm{mg} / \mathrm{kg}$ b.w, the equivalent therapeutic dose for adult male rat was $1.44 \mathrm{mg} /$ rat which calculated using Paget and Barnes (1964). Each tablet $20 \mathrm{mg}$ was dissolved in $10 \mathrm{ml}$ distilled water. Each rat was given $0.72 \mathrm{ml}$ (contained $1.44 \mathrm{mg}$ of atorvastatin) orally through a gastric tube once daily. The human therapeutic dose is ranged from 10 to $80 \mathrm{mg} /$ day (Brunton et al., 2011).

\section{Animals}

Twelve adult male albino rats weighing $200 \pm 20$ g were used in this work. The animals were fed on balanced rat chow and water. They were housed under a 12/12 h light/dark cycle, with free access of water. The room temperature was maintained at $25^{\circ} \mathrm{C}$. The rats were isolated for 2 weeks before the beginning of the experiment for acclimatization. Throughout the experiment, the rats were housed in the animal house. They were divided into two groups as follows:

1. Control group: It consisted of six adult male albino rats, was given $0.72 \mathrm{ml}$ distilled water/rat orally daily dose for 4 weeks.

2. Atorvastatin-treated group: It consisted of six adult male albino rats. Each rat was given $0.72 \mathrm{ml}$ distilled water (contained $1.44 \mathrm{mg}$ of atorvastatin) orally as a single daily dose for 4 weeks.

\section{Light Microscopic Study}

After anesthetization, organs (kidney, liver, and testis) were removed then used for light microscopic study. Organs were fixed by immersion in Bouin's solution for 2 days. The specimen was dehydrated in ascending grades of ethyl alcohol and cleared in benzene. The specimens were impregnated for three changes in paraffin and were finally embedded in paraffin wax. The paraffin blocks were cut into serial transverse sections at $5 \mu \mathrm{m}$ thick with a rotary microtome. Successive transverse paraffin sections were attached to an albumenized glass slides, then stained with hematoxylin and eosin stain (Bancroft and Gamble, 2008).

\section{RESULTS}

In light microscopic examination, two to three slides from each rat organs in every group and four fields from each slide were randomly examined, to detect any abnormalities as compared with the controls.

\section{Histological Effect of Atorvastatin on Kidney}

The cases investigated as the indicator of kidney tissue damage include the presence of acute tubular necrosis, cell swelling, hyperemia, glomerular, and Bowman capsules (BCs) size. The control group shows normal BC, with normal tubules [Figure 1]. The group, which received drugs of atorvastatin, showed the frequency in all mentioned lesions, with focal tubular edema and glomerular atrophy (GA) [Figure 2].

\section{Histological Effect of Atorvastatin on Liver}

Sections of hepatic tissue of Group I (control) showing normal central vein $(\mathrm{CV})$, where hepatocytes radiating from the $\mathrm{CV}$, normal spaced - sinusoids [Figure 2a]. Atorvastatin-exposed rats for 4 weeks revealed foci of necrosis, cytoplasmic vacuolization [Figure 2b], and inflammatory cellular infiltration.

\section{Histological Effect of Atorvastatin on Testis}

Sections of the testes revealed the presence of seminiferous tubules (ST) with multi rows of spermatogenic cells; their lumen appears to be filled with spermatozoa (SP). Interstitial spaces contain blood vessels and few interstitial cells [Figure 3a]. Testicular changes in experimental Group 2 included degenerative changes in the ST as shown by the presence of wide almost spaces between the sections of tubules; their diameter (longitudinal section) was less than

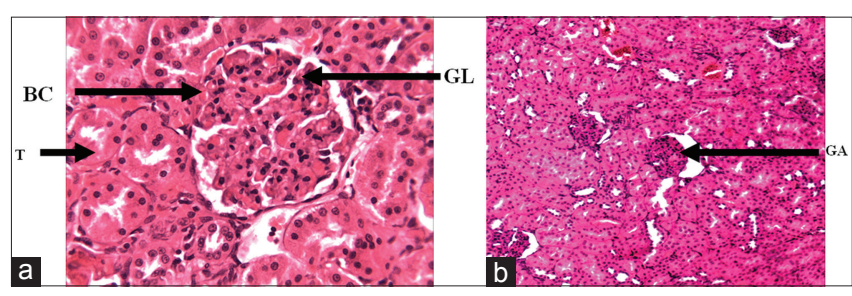

Figure 1: Photomicrographs of histological sections of kidney stained with hematoxylin and eosin $\times 400$ (a) $\times 100$ (b); (a) images of glomeruli and renal tubules from control group show normal glomerulus, Bowman capsule, and tubules (T). (b) Atorvastatintreated groups show glomerular atrophy

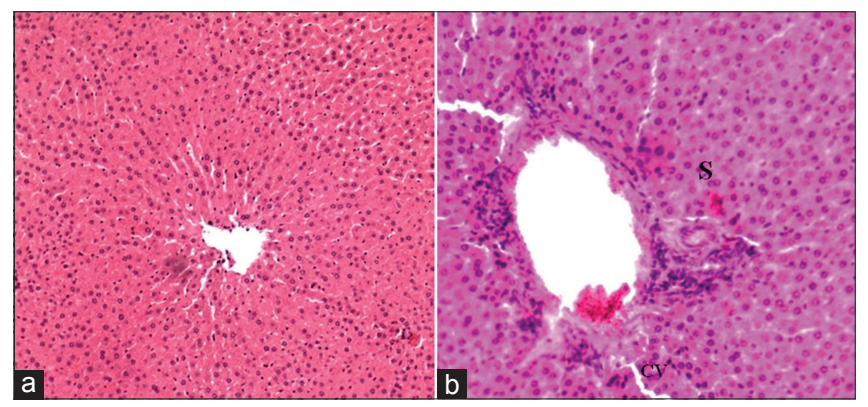

Figure 2: (a) Photomicrograph of the liver of control animal showing normal spaced sinusoids (S) and central vein (CV) (hematoxylin and eosin $\times 1001 \mathrm{a}$ ), with round polygonal cells with spherical nucleus ( $\times 4001$ b). (b) Atorvastatin-treated group showing foci of lymphocyte accumulation (L), dilation mainly around the $\mathrm{CV}$, disrupting liver cell plate 


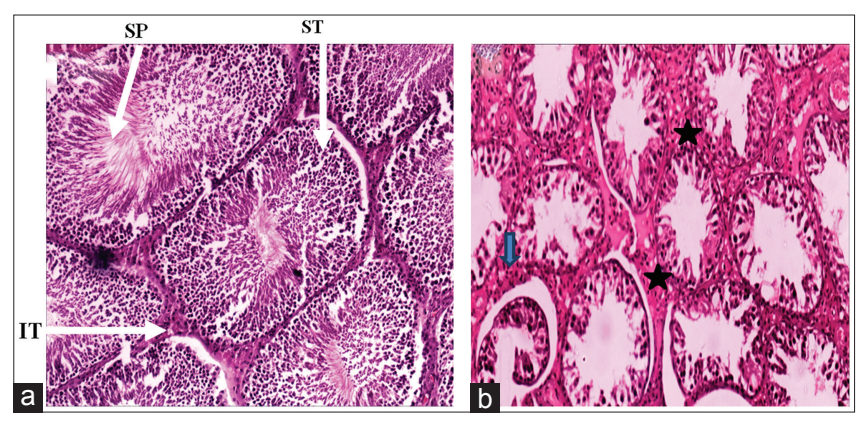

Figure 3: Photomicrograph of transverse section of the testis: (a) Control groups show the testicular capsule which is showed the seminiferous tubules (STs) which contain numerous spermatozoa. The STs are separated by the interstitial tissues (IT) (hematoxylin and eosin $\times 400$ ). (b) Atorvastatin-treated group severely congested and dilated blood vessels (black stars), and the IT (blue arrow)

the control and first experimental group. The lining of the ST contains empty spaces, cells appear to be loose and their lumens are wide and appear to be empty [Figure 3b].

\section{DISCUSSION}

In the present work, oral administration of atorvastatin for adult male albino rats for 4 weeks (Group II) leads to deleterious changes in their kidneys includes focal tubular edema and GA. This study disagreement with other studies that done in this field, Zahr et al. (2018) who stated treatment with atorvastatin significantly improved glomerular tuft area, Jaikumkao et al. (2016) reached to that atorvastatin has a renoprotective effect against gentamicininduced nephrotoxicity by decreasing overoxidation in the kidney, and Wang et al. (2017) who reported that atorvastatin possesses anti-inflammatory properties and has been demonstrated to exert protective effects against renal injury. On the other hand, this finding is contrary to Mizugushi (2004) who stated that atorvastatin $20 \mathrm{mg}$ significantly decreased tissue transforming growth factorbeta, resulting in a decrease in renal tubular damage and interstitial fibrosis. The possible cause of the congestion and vasodilatation effects of atorvastatin can be explained by Undas et al. (2014), who reported that statins therapy might affect several steps of the blood coagulation cascade, including downregulation of tissue factor expression, increased protein $\mathrm{C}$ activity and factor Va inactivation, and enhanced thrombomodulin expression.

Furthermore, the results obtained from this study also showed that degenerative changes in the ST, this is in line with Brugnon (2014), that stated atorvastatin by healthy and normocholesterolemic subjects significantly affected their sperm parameters (vitality, number, motility, morphology, and acrosome reaction), also Pons-Rejraji (2014) observed that a 5 -month atorvastatin intake $(10 \mathrm{mg} / \mathrm{d})$ induced deleterious effects on testicular, prostatic, and epididymal functions in human. It also decreased the total number of SP in ejaculate and sperm vitality and increased morphological abnormalities.

Liver sections of atorvastatin-exposed rats revealed foci of necrosis, cytoplasmic vacuolization, and inflammatory cellular infiltration; this finding is in line with Hoofnagle (2017), who stated that atorvastatin may be associated with an idiosyncratic hepatic injury, which is uncommon but sometimes may lead to acute liver failure, also Pal et al., 2015, reported that the risk of hepatotoxicity was increased in the first 6 months of atorvastatin treatment and investigated that administration of atorvastatin altered the pro-oxidant-antioxidant status of the liver by reducing intracellular glutathione level, antioxidant enzymes activities, and increasing intracellular lipid peroxidation.

\section{CONCLUSIONS}

This study identifies histological changes as early targets of drugs action that may contribute to milder symptoms of nephrotoxicity, hepatitis, and testicular dysfunction.

\section{REFERENCES}

Bancroft, J. D. and M. Gamble. 2008. Theory and Practice of Histological Techniques. $6^{\text {th }}$ ed. Churchill Livingstone, London. p340-348.

Bosch, X. A., E. B. Poch and J. M. Grau. 2009. Rhabdomyolysis and acute kidney injury. N. Engl. J. Med. 361: 62-72.

Brugnon, F. 2014. Evaluation of atorvastatin efficacy and toxicity on spermatozoa, accessory glands and gonadal hormones of healthy men: A pilot prospective clinical trial. Reprod. Biol. Endocrinol. 12(1): 1-12.

Brunton, L. L., B. A. Chabner and B. C. Knollmann. 2011. Goodman and Gilman's: The Pharmacological Basis of Theraputics. 12 $2^{\text {th }}$ ed. McGraw Hill Medical, New York, Chicago and San Francisco. p877-878.

Goldstein, J. L. and M. S. Brown. 1990. Regulation of the mevalonate pathway. Nature. 343: 425-30.

Hoofnagle, J. H. 2017. Identification and Characterization of Fenofibrate-Induced Liver Injury. Digestive Diseases and Sciences. Springer, US.

Jaikumkao, K., A. Pongchaidecha, N. Chattipakorn, V. Chatsudthipong, S. Promsan, P. Arjinajarn and A. Lungkaphin. 2016. Atorvastatin improves renal organic anion transporter 3 and renal function in gentamicin-induced nephrotoxicity in rats. Exp. Physiol. 101(6): 743-753.

Miller, M. 2009. Commentary dyslipidemia and cardiovascular risk : The importance of early prevention. QJM. 102(9): 657-667.

Mizugushi, Y., A. Miyajima, T. Kosaka, T. Asano and M. Hyakawa. 2004. Atorvastatin ameliorates renal tissue damage in unilateral ureteral obstruction. J. Urol. Dec. 172(6): 2456-2459.

Mostafa, A., A. F. Mohammed and S. M. Hanafi. 2015. Effect of atorvastatin on the testis of adult male albino, Al Azhar Assiut Med. J. 13(4): 100-118.

Paget, G. C. and J. M. Barnes. 1964. Toxicity in Evaluation of the 
Drug Activities. Pharmacometric ed. Lournace and bacharachai. Academic press, London and New York. p1-13.

Pal, S., M. Ghosh, S. Ghosh, S. Bhattacharyya and P. C. Sil. 2015. Atorvastatin induced hepatic oxidative stress and apoptotic damage via MAPKs, mitochondria, calpain and caspase12 dependent pathways. Food Chem. Toxicol. 83: 36-47.

Pasternak, R. C., S. C. Smith and C. N. BaireyMerz. 2002. ACC/AHA/ $\mathrm{NHLBI}$ clinical advisory on the use and safety of statins. Stroke. 33: 2337-2341.

Pons-Rejraji, H., F. Brugnon, B. Sion, S. Maqdasy, G. Gouby, B. Pereira, G. Marceau, A. Gremeau, J. Drevet, G. Grizard, L. Janny and I. Tauveron. 2014. Evaluation of atorvastatin efficacy and toxicity on spermatozoa, accessory glands and gonadal hormones of healthy men: A pilot prospective clinical trial. Reprod. Biol. Endocrinol. 12: 65-66.

Schmechel, A., M. Grimm, A. H. El Armouche and T. Eschenhagen. 2009. Treatment with atorvastatin partially protects the rat heart from harmful catecholamine effects. Cardiovasc. Res. 82(1): 100-106.

Undas, A., K. E. Brummel-Ziedins and K. G. Mann. 2014. Anticoagulant effects of statins and their clinical implications. Thromb. Haemost. 111(3): 392-400.

Vanholder, R., M. S. Sever, E. Erek and N. Lameire. 2000 Rhabdomyolysis. J. Am. Soc. Nephrol. 11(8): 1553-1561.

Wang, Q., Y. Y. Su, Y. Q. Li, Y. F. Zhang, S. Yang, J. L. Wang and H. Y. Li. 2017. Atorvastatin alleviates renal ischemia-reperfusion injury in rats by promoting M1-M2 transition. Mol. Med. Rep. 15(2): 798-804.

Wierzbicki, A. S., J. A. Herd, C. M. Ballantyne and J. A. Farmer. 1999. Thrombotic vascular events after change of statin. Lancet. 353(9155): 845.

Zahr, R. S., P. Chappa, H. Yin, L. A. Brown, K. I. Ataga and D. R. Archer. 2018. Renal protection by atorvastatin in a murine model of sickle cell nephropathy. Br. J. Haematol. 181(1): 111-121. 